\title{
Denoising Sinyal EEG dengan Algoritma Recursive Least Square dan Least Mean Square
}

\section{EEG Signal Denoising with Recursive Least Square and Least Mean Square Algorithms}

\author{
Nor Kumalasari Caecar Pratiwi ${ }^{1}$, Rita Magdalena ${ }^{2}$, Yunendah Nur Fuadah ${ }^{3}$, Sofia Saidah ${ }^{4}$, \\ Syamsul Rizal ${ }^{5}$, Muhamad Rokhmat Isnaini ${ }^{6}$ \\ Fakultas Teknik Elektro, Telkom University \\ Jl. Telekomunikasi No.1 Bandung 40257, telp (022) 7566456 \\ caecarnkcp@telkomuniversity.ac.id ${ }^{1 *}$, ritamagdalena@ telkomuniversity.ac.id ${ }^{2}$, \\ yunendah@telkomuniversity.ac.id ${ }^{3}$, sofiasaidahsfi@ telkomuniversity.ac.id ${ }^{4}$, \\ syamsul@telkomuniversity.ac.id ${ }^{5}$, isnaini.isnen@gmail.com ${ }^{6}$
}

\begin{abstract}
Abstrak -EEG mengukur fluktuasi tegangan yang dihasilkan dari arus ionik yang beredar sepanjang neuron otak. Dalam pengaturan eksperimental, sinyal EEG sering terkontaminasi dengan berbagai noise akibat gerakan otot dan jantung. Noise dengan magnitudo yang lebih tinggi dari sinyal aslinya akan merusak sinyal EEG dan bisa berakibat fatal dalam analisis diagnosa. Sehingga diperlukan sebuah sistem denoising yang mampu secara maksimal mengurangi noise, tanpa menghilangkan komponen informasi penting dari sinyal EEG. Salah satu algoritma yang dapat digunakan dalam mereduksi noise pada sinyal biomedis adalah RLS dan LMS. Keuntungan utama dari penggunaan adaptif filtering termasuk RLS dan LMS adalah dapat digunakan pada lingkungan non-stasioner. Tujuan penelitian adalah melakukan uji perbandingan performansi filtering RLS dan LMS dalam mereduksi noise pada sinyal EEG. Parameter performansi yang diukur adalah waktu komputasi, MSE, SNR, dan PSNR. Dari hasil pengujian, diperoleh bahwa adaptif filtering dengan RLS dan LMS mampu mereduksi noise pada sinyal EEG dengan baik. Filter LMS memiliki kelebihan pada waktu komputasinya yang singkat, rata-rata waktu komputasi filter LMS selama 0.7 detik, jauh berbeda dengan filter RLS yang membutuhkan waktu sampai dengan 113 detik. Tetapi kehandalan sistem dari sisi MSE, SNR dan PSNR untuk filter LMS masih berada dibawah RLS untuk intensitas noise yang rendah. Besarnya parameter SNR dan PSNR pada filter RLS cenderung lebih stabil pada intesitas noise $10 \mathrm{~dB}, 20 \mathrm{~dB}$, dan $30 \mathrm{db}$. Hal berbeda terjadi pada denoising dengan menggunakan filter LMS, terjadi perubahan SNR yang signifikan dari $16.14 \mathrm{~dB}$ pada noise $10 \mathrm{~dB}, 21.09 \mathrm{~dB}$ untuk noise sebesar $20 \mathrm{~dB}$, dan $25.81 \mathrm{~dB}$ untuk intensitas noise sebesar $30 \mathrm{~dB}$.
\end{abstract}

Kata Kunci: Electroencephalography, Recursive Least Square, Least Mean Square, Mean Square Error, Signal to Noise Ratio, Peak Signal to Noise Ratio

Abstract -EEG measures the voltage fluctuations that result from ionic currents circulating along brain neurons. In experimental settings, EEG signals are often contaminated with various noise due to muscle and heart movements. Noise which has a magnitude higher than the original signal will damage the EEG

TELKA, Vol.5, No.2, November 2019, pp. 122 129

ISSN (e): 2540-9123

ISSN (p): 2502-1982 
signal and could be fatal in diagnostic analysis. So we need a denoising system that is able to reduce noise optimally, without removing important information components from the EEG signal. One algorithm that can be used in reducing noise in biomedical signals is RLS and LMS. The main advantage of using this method is that it can be used in non-stationary environments. The purpose of this study is to conduct a comparison test of RLS and LMS filtering performance in reducing noise in EEG signals. The performance was measured using several parameters, such as computational time, MSE, SNR, and PSNR. The result show that adaptive filtering with RLS and LMS are able to reduce noise in EEG signals well. The performance using LMS filters has better performance on computation time, where the average computation time of LMS is 0.7 seconds and RLS is 113 seconds. Meanwhile, the reliability of the system in terms of MSE, SNR and PSNR for RLS is better than LMS. The magnitude of SNR and PSNR parameters in RLS filters tends to be more stable in noise intensity of $10 \mathrm{~dB}, 20 \mathrm{~dB}$ and $30 \mathrm{db}$. Different with the LMS filter, there was a significant change in $S N R$ of $16.14 \mathrm{~dB}$ at $10 \mathrm{~dB}$ noise, $21.09 \mathrm{~dB}$ for noise of $20 \mathrm{~dB}$ and $25.81 \mathrm{~dB}$ for noise intensity of $30 \mathrm{~dB}$.

Keywords: Electroencephalography, Recursive Least Square, Least Mean Square, Mean Square Error, Signal to Noise Ratio, Peak Signal to Noise Ratio

\section{Pendahuluan}

Electroencephalography (EEG) adalah tes elektrofisiologis non-invasif yang memantau aktivitas listrik otak melalui beberapa elektroda yang diletakkan di kulit kepala. EEG mengukur fluktuasi tegangan yang dihasilkan dari arus ionik yang beredar sepanjang neuron otak [1]. Sinyal Electroencephalogram (EEG) telah digunakan secara luas dibanyak bidang, seperti ilmu saraf, penelitian psikofisiologis, neurolinguistik dan banyak lagi [2]. EEG telah dieksplorasi dalam studi klinis termasuk gangguan otak, gangguan tidur, epilepsi, dan disfungsi neurologis lainnya. Dalam pengaturan eksperimental, sinyal EEG yang direkam sering terkontaminasi dengan berbagai noise. Noise yang muncul pada perekaman sinyal EEG diantaranya akibat gerakan otot dan jantung. Noise dengan magnitudo yang lebih tinggi dari sinyal aslinya akan merusak sinyal EEG dan bisa berakibat fatal dalam analisis diagnosa. Dilatarbelakangi hal tersebut, diperlukan sebuah sistem denoising yang tepat, pemilihan filter denoising yang mampu secara maksimal mengurangi noise tanpa menghilangkan komponen informasi penting dari sinyal. Pengurangan noise pada citra digital adalah skema pre-processing yang penting untuk dilakukan, termasuk pada segmentasi gambar medis [3]. Salah satu algoritma yang dapat digunakan dalam mereduksi noise pada sinyal biomedis adalah Recursive Least Square (RLS) dan Least Mean Square (LMS). Keuntungan utama dari penggunaan adaptif filtering termasuk RLS dan LMS adalah dapat digunakan pada lingkungan non-stasioner, dikarenakan sistem secara terus-menerus mampu beradaptasi untuk perubahan statistik dalam data [4]. Tujuan dari penelitian ini adalah melakukan uji perbandingan performansi filtering RLS dan LMS dalam denoising noise pada sinyal EEG. Parameter performansi yang diukur adalah waktu komputasi, Mean Square Error (MSE), Signal to Noise Ratio (SNR) dan Peak Signal to Noise Ratio (PSNR).

Telah banyak penelitian terkait denoising untuk sinyal biomedis, termasuk sinyal EEG. Diantaranya adalah penelitian yang dilakukan oleh Xun Chen [5]. Dalam penelitiannya, Chen menggunakan kombinasi Multivariate Empirical Mode Decomposition (MEMD) dan Canonical Correlation Analysis (CCA). Hasil eksperimen menunjukkan bahwa metode yang diusulkan mampu untuk mereduksi noise yang diakibatkan oleh pergerakan otot dalam beberapa saluran kanal EEG. Studi lain dilakukan oleh Edson Estrada [6], dalam mengeksplorasi penerapan metode denoising sinyal EEG dengan metode wavelet. Hasil menunjukkan bahwa kombinasi soft thresholding pada detailed wavelet koefisien memberikan kinerja yang lebih baik dengan MSE yang lebih kecil dan SNR yang lebih besar. Pranjali Gajbhiye [7] dalam penelitiannya yang berjudul "Novel Approaches for the Removal of Motion Artifact from EEG Recordings", memberikan hasil bahwa metode filtering Multiresolution Total Variation (MTV) and Multiresolution Weighted Total Variation (MWTV) memiliki kinerja denoising yang lebih baik. Performansi sitem ditunjukkan dengan SNR rata-rata sebesar 29,12 dB (MTV) dan 29,29 dB (MWTV) dengan koefesien korelasi sebesar 68,56\%, dan 67,51\%. Penelitian dengan judul 
"Biomedical Signals Analysis by DWT Signal Denoising with Neural Networks" [8] menganalisa secara mendalam proses denoising dan compressing pada sinyal EEG, ECG dan EMG dengan transformasi wavelet diskrit. Performansi sistem diuji untuk berbagai mother wavelet, seperti haar, daubiches, symlet, dan bior. Sepideh Hajipour Sardouie [9] dalam penelitiannya menyimpulkan bahwa Time-Frequency-Generalized Eigen Value Decomposition (TF-GEVD) dan Time-Frequency-Denoising Source Separation (TF-DSS) memiliki kehandalan yang lebih tinggi jika dibandingkan dengan Canonical Correlation Analysis (CCA) dan Independent Component Analysis (ICA) dalam proses menghilangkan noise akibat pergerakkan otot pada sinyal EEG. Penelitian terkait reduksi noise pada sinyal EEG juga dilakukan oleh Kafiul Islam [10]. Dalam tulisannya, disajikan metode yang mampu memetakan probabilitas noise pada sinyal EEG berdasarkan ciri statistik entropi, kurtosis, skewness, dan Periodic Waveform Index (PWI). Hasil eksperimental membuktikan kehandalan metode yang dapat mengurangi noise sinyal EEG dengan sedikit distorsi pada sinyal aslinya. Harender dalam tulisannya yang berjudul "EEG Signal Denoising based on Wavelet Transform" menyajikan metode denoising berdasarkan kombinasi Stationary Wavelet Transform (SWT), universal threshold, statistical threshold dan Discrete Wavelet Transform (DWT). Hasilnya menunjukkan peningkatan kinerja yang signifikan pada parameter Signal to Artifacts Ratio (SAR), Correlation Coefficient (CC) dan Normalized Mean Squared error (NMSE) [11].

\section{Metode Penelitian}

Algoritma Recursive Least-Squares (RLS) dan Least Mean Square (LMS) termasuk dalam metode adaptif filtering. Proses menghilangkan noise dari sinyal asli dengan menggunakan adaptif filtering ditunjukkan oleh Gambar 1 dibawah ini.

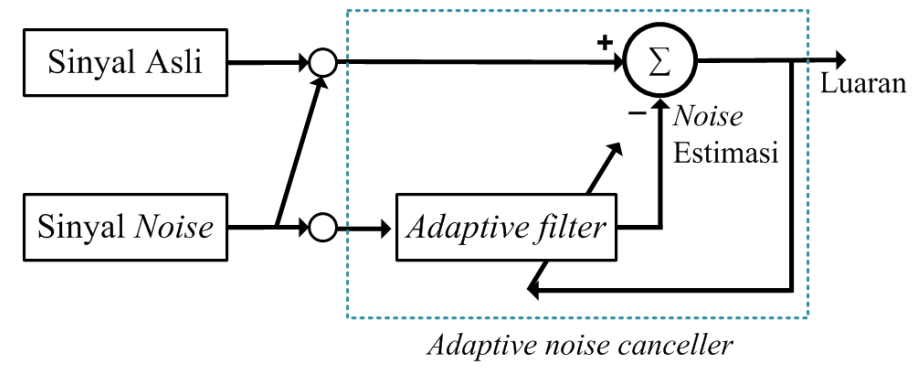

Gambar 1. Denoising dengan Adaptif Filtering [12]

Algoritma RLS menawarkan tingkat konvergensi yang lebih baik pada sinyal input dengan korelasi yang tinggi, namun demikian, kompleksitas komputasi juga akan tinggi [13]. Dalam algoritma RLS, bobot filter diperbarui menggunakan persamaan (1) - (3) [14]:

$$
\begin{gathered}
w(n)=\overline{w^{T}}(n-1)+k(n) \overline{e_{n-1}}(n) \\
k(n)=\frac{u(n)}{\left(\lambda+X^{T}(n) u(n)\right)} \\
u(n)=\overline{w_{\lambda}^{-1}}(n-1) X(n)
\end{gathered}
$$

Persamaan (2) dan (3) digunakan untuk mencari gain vector filter, dimana $\lambda$ adalah nilai positif konstan yang kurang dari 1 , sangat mendekati 1 . Sinyal keluaran filter $y(n)$ dihitung dengan persamaan (4) dan (5) [14]: 


$$
\begin{gathered}
\overline{y_{n-1}}(n)=\overline{w^{T}}(n-1)+X(n) \\
\overline{e_{n-1}}(n)=d(n)-\overline{y_{n-1}}(n)
\end{gathered}
$$

Dimana $X(n)$ adalah masukkan sistem, $d(n)$ sinyal yang diinginkan, dan $e(n)$ adalah error pada output. Konfigurasi adaptif filtering ditunjukkan oleh Gambar 2 [14].

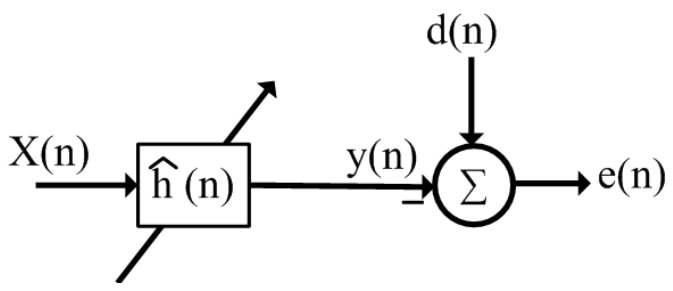

Gambar 2. Konfigurasi adaptif filtering.

Diagram blok denoising dengan algoritma LMS ditunjukkan pada Gambar 3 [15].

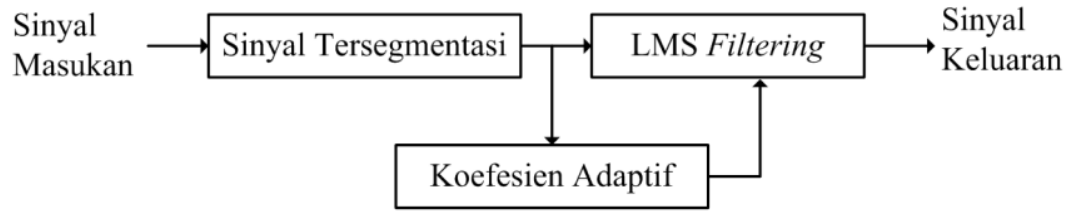

Gambar 3. Denoising dengan Algoritma Least Mean Square (LMS).

Algoritma LMS dibuat oleh Widrow dan Hoff pada tahun 1960 untuk digunakan dalam pelatihan neural network. Algoritma LMS menggunakan perkiraan gradient dalam mencari vektor bobot $w_{n}$ yang diinginkan. Sinyal masukkan adalah penggabungan antara sinyal yang diinginkan $d(n)$ dan sinyal noise $v(n)$, sebagaimana ditunjukkan oleh persamaan (6) [15]

$$
u(n)=d(n)+v(n) .
$$

Variabel filter memiliki respon impuls terbatas (finite impulse response - FIR). Koefisien filter dengan orde filter $p$ didefinisikan dengan persamaan (7)

$$
W_{n}=\left[w_{n}(0), w_{n}(1), \ldots, w_{n}(p)\right]^{T} .
$$

Sinyal error $e(n)$ adalah selisih antara sinyal yang sebenarnya dan sinyal hasil estimasi, dinyatakan dengan persamaan (8)

$$
e(n)=d(n)-\hat{d}(n) .
$$

Sinyal estimasi $\hat{d}(n)$ merupakan hasil konvolusi antara koefisien filter $W_{n}$ dan respon impuls $u(n)$.

Data yang akan digunakan dalam penelitian ini adalah sinyal otak bersih atau cleaned EEG signal yang diambil dari bank sinyal PhysioNet [15]. Sinyal noise yang digunakan pada penelitian ini merupakan sinyal AWGN (Additive White Gaussian Noise) dengan variasi intensitas sebesar $10 \mathrm{~dB}, 20 \mathrm{~dB}$, dan $30 \mathrm{~dB}$. Alur penelitian diilustrasikan pada Gambar 4. 


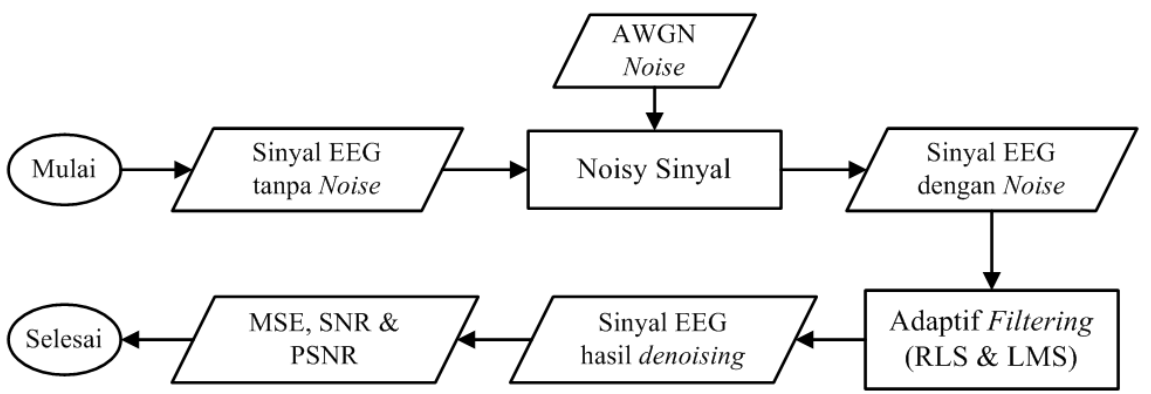

Gambar 4. Alur metode penelitian denoising sinyal EEG dengan Algoritma RLS dan LMS.

Penelitian dimulai dengan mempersiapkan lima sinyal EEG original yang akan digunakan sebagai objek penelitian. Lima sinyal tersebut berasal dari lima pasien, dengan kondisi kesehatan yang sama. Data sinyal original yang akan digunakan adalah data sinyal otak bersih yang diambil dari bank signal Physionet. Tahap selanjutnya adalah menambahkan noise kedalam sinyal original. Sinyal yang ditelah ditambahkan noise, akan dilakukan analisis proses denoising dengan menggunakan algoritma adaptive filter. Selanjutnya, sinyal denoising akan direkonstruksi. Kinerja metode adaptive filtering akan dianalisis melalui parameter - parameter MSE, SNR dan PSNR.

\section{Hasil dan Pembahasan}

Skenario pengujian terhadap sistem denoising sinyal EEG menggunakan metode adaptive filtering algoritma RLS dan LMS. Data sinyal EEG yang akan diuji berjumlah 5, diambil dari lima pasien berbeda, dengan kondisi kesehatan yang sama (eegsignal1, eegsignal2, eegsignal3, eegsignal 4 dan eegsignal 5). Setiap sinyal di-sampling dengan frekuensi sebesar $2048 \mathrm{~Hz}$, dan sampling interval $0.00048 \mathrm{mV}$. Kemudian noise yang akan digunakan adalah Additive White Gaussian Noise dengan variasi intensitas SNR yang akan diuji sebesar $10 \mathrm{~dB}, 20 \mathrm{~dB}$ dan $30 \mathrm{~dB}$. Proses denoising sinyal EEG dengan intensitas noise sebesar $30 \mathrm{~dB}$ ditunjukkan pada Gambar 5.

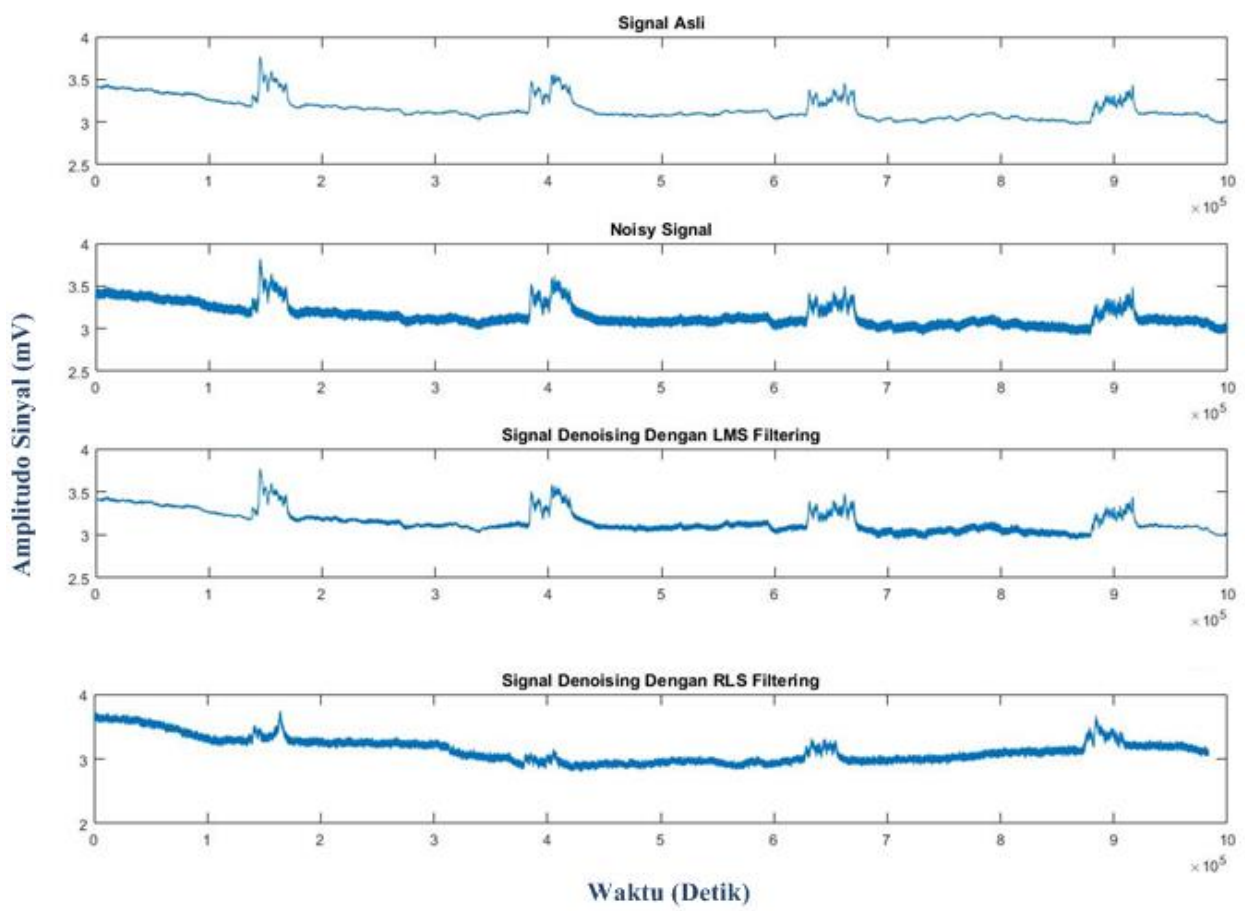

Gambar 5. Proses denoising sinyal EEG dengan intensitas noise sebesar $30 \mathrm{~dB}$. 
Setelah melakukan pengujian pada 5 sinyal input EEG dengan LMS dan RLS, masingmasing sinyal di uji coba sebanyak 3 kali percobaan, dan diperoleh nilai rata-rata untuk parameter waktu komputasi, MSE, SNR dan PSNR sebagaimana dimuat pada Tabel 1.

Tabel 1. Kinerja sistem denoising dengan intensitas noise sebesar $10 \mathrm{~dB}$.

\begin{tabular}{|c|c|c|c|c|c|c|c|c|c|}
\hline \multirow{2}{*}{ Sinyal } & \multirow{2}{*}{$\begin{array}{l}\text { Pengujian } \\
\text { Ke- }\end{array}$} & \multicolumn{2}{|c|}{$\begin{array}{l}\text { Waktu Komputasi } \\
\text { (Detik) }\end{array}$} & \multicolumn{2}{|c|}{ MSE } & \multicolumn{2}{|c|}{ SNR (dB) } & \multicolumn{2}{|c|}{ PSNR (dB) } \\
\hline & & $L M S$ & $R L S$ & $L M S$ & $R L S$ & LMS & RLS & LMS & RLS \\
\hline \multirow{4}{*}{ Eegsignal1 } & 1 & 0.7017 & 122.16 & 0.0067 & 0.0002 & 16.40 & 24.19 & 16.94 & 24.73 \\
\hline & 2 & 0.7071 & 115.98 & 0.0083 & 0.0001 & 15.93 & 25.57 & 16.47 & 26.11 \\
\hline & 3 & 0.7098 & 113.70 & 0.0076 & 0.0027 & 16.14 & 18.35 & 16.68 & 18.89 \\
\hline & 1 & 0.6994 & 111.22 & 0.0103 & 0.0022 & 16.54 & 19.89 & 17.29 & 20.64 \\
\hline \multirow[t]{3}{*}{ Eegsignal2 } & 2 & 0.6962 & 111.16 & 0.0098 & 0.0004 & 16.65 & 38.51 & 17.40 & 39.26 \\
\hline & 3 & 0.6918 & 112.50 & 0.0133 & 0.0001 & 15.99 & 25.77 & 16.74 & 26.52 \\
\hline & 1 & 0.7155 & 113.86 & 0.0111 & 0.0016 & 16.43 & 20.69 & 17.03 & 21.29 \\
\hline \multirow[t]{3}{*}{ Eegsignal3 } & 2 & 0.7303 & 113.80 & 0.0120 & 0.0005 & 16.27 & 23.02 & 16.87 & 23.62 \\
\hline & 3 & 0.7043 & 113.67 & 0.0130 & 0.0000 & 16.08 & 35.62 & 16.68 & 36.22 \\
\hline & 1 & 0.7149 & 111.71 & 0.0067 & 0.0001 & 15.84 & 25.82 & 16.52 & 26.50 \\
\hline \multirow[t]{3}{*}{ Eegsignal4 } & 2 & 0.7040 & 113.65 & 0.0060 & 0.0007 & 16.09 & 20.69 & 16.76 & 21.37 \\
\hline & 3 & 0.6882 & 113.04 & 0.0074 & 0.0002 & 15.64 & 23.88 & 16.32 & 24.55 \\
\hline & 1 & 0.7025 & 113.09 & 0.0064 & 0.0005 & 15.97 & 21.35 & 16.73 & 22.12 \\
\hline \multirow[t]{2}{*}{ Eegsignal5 } & 2 & 0.7101 & 114.26 & 0.0054 & 0.0002 & 16.34 & 23.07 & 17.10 & 23.84 \\
\hline & 3 & 0.7093 & 114.46 & 0.0069 & 0.0000 & 15.80 & 27.29 & 16.57 & 28.06 \\
\hline \multicolumn{2}{|c|}{ Rata-rata } & 0.7057 & 113.88 & 0.0087 & 0.0006 & 16.14 & 24.91 & 16.81 & 25.58 \\
\hline
\end{tabular}

Dari Tabel 1 diatas, terlihat bahwa rata-rata waktu komputasi filter RLS jauh lebih besar dibandingkan dengan LMS. Jika LMS rata-rata mampu menyelesaikan proses denoising selama 0.7 detik, jauh berbeda dengan filter RLS yang membutuhkan waktu sampai dengan 113 detik. Tetapi, waktu komputasi yang lama pada RLS dibayar dengan performansi yang cukup handal, terlihat dari parameter MSE, SNR dan PSNR yang lebih unggul dibandingkan dengan algoritma LMS seperti ditunjukkan pada Tabel 2.

Tabel 2. Kinerja sistem denoising dengan intensitas noise sebesar $20 \mathrm{~dB}$.

\begin{tabular}{|c|c|c|c|c|c|c|c|c|c|}
\hline \multirow{2}{*}{ Sinyal } & \multirow{2}{*}{$\begin{array}{c}\text { Pengujian } \\
\text { Ke- }\end{array}$} & \multicolumn{2}{|c|}{$\begin{array}{l}\text { Waktu Komputasi } \\
\text { (Detik) }\end{array}$} & \multicolumn{2}{|c|}{ MSE } & \multicolumn{2}{|c|}{ SNR (dB) } & \multicolumn{2}{|c|}{ PSNR (dB) } \\
\hline & & $L M S$ & $R L S$ & $L M S$ & $R L S$ & LMS & RLS & LMS & RLS \\
\hline \multirow{4}{*}{ Eegsignal1 } & 1 & 0.7244 & 113.57 & 0.0006 & 0.0007 & 21.49 & 21.25 & 22.03 & 21.79 \\
\hline & 2 & 0.7034 & 113.41 & 0.0008 & 0.0007 & 21.14 & 21.31 & 21.68 & 21.85 \\
\hline & 3 & 0.7211 & 112.80 & 0.0007 & 0.0001 & 21.38 & 26.10 & 21.92 & 26.64 \\
\hline & 1 & 0.6928 & 111.66 & 0.0013 & 0.0001 & 21.02 & 27.66 & 21.77 & 28.41 \\
\hline \multirow[t]{3}{*}{ Eegsignal2 } & 2 & 0.6899 & 110.91 & 0.0010 & 0.0001 & 21.58 & 25.88 & 22.33 & 26.63 \\
\hline & 3 & 0.7028 & 110.86 & 0.0013 & 0.0004 & 20.98 & 23.65 & 21.73 & 24.40 \\
\hline & 1 & 0.7112 & 119.71 & 0.0017 & 0.0006 & 20.53 & 22.66 & 21.13 & 23.26 \\
\hline \multirow[t]{3}{*}{ Eegsignal3 } & 2 & 0.7034 & 113.43 & 0.0014 & 0.0001 & 20.93 & 27.95 & 21.53 & 28.56 \\
\hline & 3 & 0.7112 & 117.64 & 0.0013 & 0.0034 & 21.08 & 19.02 & 21.68 & 19.62 \\
\hline & 1 & 0.7002 & 110.83 & 0.0006 & 0.0013 & 21.08 & 19.49 & 21.76 & 20.16 \\
\hline \multirow[t]{3}{*}{ Eegsignal4 } & 2 & 0.6924 & 112.41 & 0.0009 & 0.0004 & 20.24 & 22.26 & 20.91 & 22.93 \\
\hline & 3 & 0.6961 & 112.24 & 0.0005 & 0.0000 & 21.55 & 29.80 & 22.22 & 30.47 \\
\hline & 1 & 0.7088 & 114.26 & 0.0008 & 0.0000 & 20.54 & 26.79 & 21.30 & 27.55 \\
\hline \multirow[t]{2}{*}{ Eegsignal5 } & 2 & 0.7038 & 113.69 & 0.0003 & 0.0003 & 22.76 & 22.44 & 23.53 & 23.21 \\
\hline & 3 & 0.7057 & 114.83 & 0.0010 & 0.0001 & 19.98 & 24.69 & 20.75 & 25.46 \\
\hline \multicolumn{2}{|c|}{ Rata-rata } & 0.7045 & 113.48 & 0.0009 & 0.0005 & 21.09 & 24.06 & 21.75 & 24.73 \\
\hline
\end{tabular}

Hal yang sama juga terjadi pada saat sinyal EEG diberikan intensitas noise sebesar $20 \mathrm{~dB}$. Dari Tabel 2 terlihat bahwa rata-rata waktu komputasi filter RLS sebesar 113.48 detik, masih jauh lebih besar dibandingkan dengan filter LMS, yang hanya membutuhkan waktu rata-rata selama 0.7 detik. Tetapi, waktu komputasi yang lama pada RLS dibayar dengan performansi yang cukup handal, terlihat dari parameter SNR sebesar $24.06 \mathrm{~dB}$ dan PSNR sebesar $24.73 \mathrm{~dB}$, lebih unggul dibandingkan dengan algoritma LMS, yang memiliki SNR dan PSNR berturut-turut sebesar 21.09 $\mathrm{dB}$ dan $21.75 \mathrm{~dB}$ sebagaimana ditunjukkan pada Tabel 3.

ISSN (e): 2540-9123

ISSN (p): 2502-1982 
Tabel 3. Kinerja sistem denoising dengan intensitas noise sebesar $30 \mathrm{~dB}$

\begin{tabular}{|c|c|c|c|c|c|c|c|c|c|}
\hline \multirow{2}{*}{ Sinyal } & \multirow{2}{*}{$\begin{array}{l}\text { Pengujian } \\
\text { Ke- }\end{array}$} & \multicolumn{2}{|c|}{$\begin{array}{l}\text { Waktu Komputasi } \\
\text { (Detik) }\end{array}$} & \multicolumn{2}{|c|}{ MSE } & \multicolumn{2}{|c|}{$\mathrm{SNR}(\mathrm{dB})$} & \multicolumn{2}{|c|}{ PSNR (dB) } \\
\hline & & $L M S$ & $R L S$ & $L M S$ & $R L S$ & LMS & RLS & LMS & RLS \\
\hline \multirow{4}{*}{ Eegsignal1 } & 1 & 0.7317 & 113.92 & 0.00001 & 0.00189 & 31.36 & 19.15 & 31.90 & 19.69 \\
\hline & 2 & 0.71 & 115.48 & 0.00004 & 0.00002 & 27.83 & 28.77 & 28.37 & 29.31 \\
\hline & 3 & 0.7083 & 114.21 & 0.00013 & 0.00065 & 25.03 & 21.48 & 25.57 & 22.02 \\
\hline & 1 & 0.7038 & 111.24 & 0.00045 & 0.00209 & 23.34 & 20.00 & 24.09 & 20.75 \\
\hline \multirow[t]{3}{*}{ Eegsignal2 } & 2 & 0.695 & 110.60 & 0.00151 & 0.00009 & 20.71 & 26.93 & 21.46 & 27.67 \\
\hline & 3 & 0.69 & 112.91 & 0.00009 & 0.00003 & 26.77 & 29.38 & 27.52 & 30.13 \\
\hline & 1 & 0.7061 & 113.42 & 0.00148 & 0.00008 & 20.80 & 27.21 & 21.41 & 27.82 \\
\hline \multirow[t]{3}{*}{ Eegsignal3 } & 2 & 0.7047 & 112.94 & 0.00019 & 0.00001 & 25.31 & 32.41 & 25.91 & 33.02 \\
\hline & 3 & 0.6981 & 113.92 & 0.00031 & 0.00048 & 24.21 & 23.25 & 24.82 & 23.85 \\
\hline & 1 & 0.7134 & 111.20 & 0.00010 & 0.00032 & 24.94 & 22.43 & 25.62 & 23.10 \\
\hline \multirow[t]{3}{*}{ Eegsignal4 } & 2 & 0.697 & 110.90 & 0.00000 & 0.00014 & 31.87 & 24.25 & 32.54 & 24.92 \\
\hline & 3 & 0.6974 & 112.33 & 0.00003 & 0.00051 & 27.59 & 24.69 & 28.27 & 25.45 \\
\hline & 1 & 0.7052 & 112.48 & 0.00016 & 0.00012 & 24.03 & 30.61 & 24.79 & 22.14 \\
\hline \multirow[t]{2}{*}{ Eegsignal5 } & 2 & 0.8784 & 112.58 & 0.00003 & 0.00001 & 27.91 & 21.46 & 28.67 & 31.38 \\
\hline & 3 & 0.7134 & 116.79 & 0.00008 & 0.00027 & 25.47 & 22.87 & 26.23 & 23.63 \\
\hline \multicolumn{2}{|c|}{ Rata-rata } & 0.7168 & 113.00 & 0.00031 & 0.00045 & 25.81 & 24.99 & 26.48 & 25.66 \\
\hline
\end{tabular}

Pada saat sinyal diberikan intensitas noise sebesar $30 \mathrm{~dB}$, masih terlihat bahwa filter LMS memilik waktu komputasi yang jauh lebih singkat dibandingkan filter RLS. Berbeda dengan hasil yang ditunjukkan pada Tabel 1 dan Tabel 2, pada saat sinyal diberikan intensitas noise $30 \mathrm{~dB}$, kinerja LMS bisa dikatakan lebih baik jika ditinjau dari parameter MSE yang lebih kecil, dan SNR serta PSNR yang lebih baik dibandingkan RLS.

Dari tiga skenario diatas, secara keseluruhan terlihat bahwa filter LMS memiliki kelebihan pada waktu komputasi yang lebih singkat, dengan rata-rata berada pada 0.7 detik, tetapi kehandalan sistem dari sisi parameter MSE, SNR dan PSNR masih berada dibawah RLS untuk intensitas noise yang rendah. Besarnya parameter SNR dan PSNR pada filter RLS cenderung lebih stabil, berada pada kisaran $24.06 \mathrm{~dB}$ sampai dengan $24.99 \mathrm{~dB}$ untuk parameter SNR, dan $24.73 \mathrm{~dB}$ sampai dengan $25.66 \mathrm{~dB}$ untuk parameter PSNR. Hal berbeda terjadi pada denoising dengan menggunakan filter LMS, terjadi perubahan SNR yang signifikan dari $16.14 \mathrm{~dB}$ pada noise $10 \mathrm{~dB}, 21.09 \mathrm{~dB}$ untuk noise sebesar $20 \mathrm{~dB}$ dan $25.81 \mathrm{~dB}$ untuk intensitas noise sebesar 30 $\mathrm{dB}$.

\section{Kesimpulan}

Dari data hasil pengujian, dapat disimpulkan bahwa adaptif filtering dengan algoritma Recursive Least Square (RLS) dan Least Mean Square (LMS) mampu mereduksi noise (denoising) pada sinyal EEG dengan baik. Filter LMS memiliki kelebihan pada waktu komputasinya yang singkat, tetapi kehandalan sistem dari sisi parameter MSE, SNR dan PSNR masih berada dibawah RLS untuk intensitas noise yang rendah. Besarnya parameter SNR dan PSNR pada filter RLS cenderung lebih stabil (tidak mengalami perubahan signifikan) pada intensitas noise $10 \mathrm{~dB}, 20 \mathrm{~dB}$ dan $30 \mathrm{db}$. Hal berbeda terjadi pada denoising dengan menggunakan filter LMS, terjadi perubahan yang signifikan (menjadi lebih baik) pada besarnya parameter SNR dan PSNR untuk intensitas noise yang semakin tinggi. Mempertimbangkan dari segi waktu komputasi yang lebih cepat, besarnya MSE, SNR dan PSNR yang lebih baik, maka dapat disimpulkan bahwa filter LMS memiliki performansi yang lebih unggul dibandingkan dengan RLS, terutama pada intensitas noise yang semakin besar.

\section{Referensi}

[1] S. Islam, A. M. El-hajj, H. Alawieh, Z. Dawy, N. Abbas, and J. El-imad, "Biomedical Signal Processing and Control EEG mobility artifact removal for ambulatory epileptic seizure prediction applications," Biomed. Signal Process. Control, vol. 55, p. 101638, 2020 . 
[2] N. Bajaj, J. Requena, F. Bellotti, R. Berta, and A. De Gloria, "Biomedical Signal Processing and Control Automatic and tunable algorithm for EEG artifact removal using wavelet decomposition with applications in predictive modeling during auditory tasks," Biomed. Signal Process. Control, vol. 55, p. 101624, 2020.

[3] C. J. Jeba and G. Suganthi, "Biomedical Signal Processing and Control An efficient denoising of impulse noise from MRI using adaptive switching modified decision based unsymmetric trimmed median filter," Biomed. Signal Process. Control, vol. 55, p. 101657, 2020.

[4] N. K. Muhsin, "Noise Removal of ECG Signal Using Recursive Least Square Algorithms," Al-Khwarizmi Eng. J., vol. 7, no. 1, pp. 13-21, 2011.

[5] X. Chen, X. Xu, A. Liu, M. J. McKeown, and Z. J. Wang, "The Use of Multivariate EMD and CCA for Denoising Muscle Artifacts from Few Channel EEG Recordings," IEEE Trans. Intrumentation Meas., vol. 67, no. 2, pp. 359-370, 2018.

[6] E. Estrada, H. Nazeran, G. Sierra, F. Ebrahimi, and S. K. Setarehdan, "Wavelet-based EEG Denoising for Automatic Sleep Stage Classification," in 21st International Conference on Electrical Communications and Computers, 2011, pp. 295-298.

[7] P. Gajbhiye, R. K. Tripathy, A. Bhattacharyya, and R. B. Pachori, "Novel Approaches for the Removal of Motion Artifact from EEG Recordings," IEEE Sens. J., vol. 1748, pp. 110, 2019.

[8] G. Kaushik, H. P. Sinha, and L. Dewan, "Biomedical Signals Analysis by DWT Signal Denoising With Neural Networks," J. Theor. Appl. Inf. Technol., vol. 62, no. 1, pp. 184198, 2014.

[9] S. H. Sardouie, M. B. Shamsollahi, L. Albera, and I. Merlet, "Denoising of ictal EEG data using semi-blind source separation methods based on time-frequency priors," IEEE $J$. Biomed. Heal. Informatics, vol. 2194, no. c, pp. 1-9, 2014.

[10] K. Islam and A. Rastegarnia, "Probability Mapping Based Artifact Detection and Wavelet Denoising based Artifact Removal from Scalp EEG for BCI Applications," in 2019 IEEE 4th International Conference on Computer and Communication Systems (ICCCS), 2019, pp. 243-247.

[11] Harender and R. K. Sharma, "EEG Signal Denoising based on Wavelet Transform," in International Conference on Electronics, Communication and Aerospace Technology ICECA 2017 EEG, 2017, pp. 758-761.

[12] A. C. M. F. S. R. M. U. Ahmed, "A study of recursive least squares (RLS) adaptive filter algorithm in noise removal from ECG signals," in 2015 International Conference on Informatics, Electronics \& Vision (ICIEV), 2015, pp. 1-6.

[13] V. Roy and S. Shukla, "Mth Order FIR Filtering for EEG denoising using Adaptive recursive Least Squares Squares Algorithm," in 2015 International Conference on Computational Intelligence and Communication Networks, 2015, pp. 1-4.

[14] J. Dhiman, S. Ahmad, and K. Gulia, "Comparison between Adaptive filter Algorithms ( LMS , NLMS and RLS )," in International Journal of Science, Engineering and Technology Research (IJSETR), 2013, vol. 2, no. 5, pp. 1100-1103.

[15] S.Arunkumar, P.Parthiban, and S. A. Kumar, "Implementation of Least Mean Square Algorithm For Sinusoidal and Audio Denoising Using FPGA," Int. J. Adv. Res. Electr. Electron. Instrum. Eng., vol. 2, no. 12, pp. 5843-5850, 2013.

[16] F. Ali, P. Rawat, and S. Malvia, "Comparative Analysis and Survey of LMS and RLS Adaptive Algorithms," Int. J. Comput. Appl., vol. 161, no. 3, pp. 26-29, 2017. 